IMAGENS \& PALAVRAS

\title{
PSICOLOGIA HISTÓRICO-CULTURAL, PEREZHIVANIE E ALÉM: UMA ENTREVISTA COM NIKOLAI VERESOV
}

\author{
Flávio Fernandes Fontes ${ }^{1}$ (D) \\ Jorge Tarcísio da Rocha Falcáo ${ }^{2}$ (1) \\ Letícia Raboud Mascarenhas de Andrade ${ }^{2}$ (D) \\ Priscila Cristine Andrade de Sousa ${ }^{2}$ (D \\ José Arnaud Marques Júnior ${ }^{2}$ (D
}

\section{Introdução}

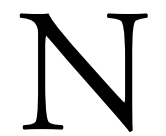

ikolai Veresov é um dos especialistas da atualidade sobre Vigotski, utilizando a vantagem de ter o russo como língua materna para melhor compreendê-lo dentro de seu contexto histórico e linguístico. Em 1999, o autor publicou o livro Undiscovered Vygotsky, com foco no início da carreira de Vigotski (até 1927) e procurando explicitar a dinâmica interna de desenvolvimento das suas ideias antes da formulação da teoria histórico-cultural propriamente dita. A partir da compreensão de que Vigotski nunca apresentou um trabalho sistemático de sua teoria e metodologia, favorecendo o aparecimento de erros conceituais e, consequentemente, metodológicos, Veresov trabalha atualmente em um livro que sistematiza a abordagem histórico-cultural e sua metodologia, projeto que vem sendo desenvolvido e divulgado pelo estudioso. $\mathrm{O}$ autor publicou cinco livros e mais de 60 artigos disponíveis em 10 idiomas. Sua produçấo traz contribuiçóes à compreensão da psicologia histórico-cultural, desfazendo mal-entendidos da apropriaçáo ocidental e aprofundando conceitos como os de mediação, dialética, zona de desenvolvimento próximo e perezhivanie, buscando situá-los sempre em sua relação com a lei genética geral do desenvolvimento cultural. $\mathrm{O}$ termo perezhivanie náo encontra no nosso idioma uma traduçáo que faça jus a todas as peculiaridades presentes no original russo, sendo "vivência" a tradução considerada mais pertinente (TOASSA; SOUZA, 2010). Trata-se de um conceito que náo foi plenamente desenvolvido por Vigotski (embora ocupe um

\footnotetext{
${ }^{1}$ Universidade Federal do Rio Grande do Norte, Faculdade de Ciências da Saúde do Trairi - Santa Cruz (RN), Brasil. E-mail: flaviofontes@outlook.com

${ }^{2}$ Universidade Federal do Rio Grande do Norte - Natal (RN), Brasil. E-mails: falcao.jorge@gmail.com; lelermandrade@gmail.com; sousapri@gmail.com; gnioarnaud@gmail.com

DOI: 10.1590/ES0101-73302019184797
} 
lugar importante em sua teoria) e que se encontra ainda em etapa de exploração no contexto da psicologia histórico-cultural.

Nikolai Veresov foi professor da educação infantil e do ensino fundamental entre os anos de 1982 e 1991. Em 1982, concluiu o mestrado em educação pelo Instituto Pedagógico de Murmansk, na Rússia. Realizou o primeiro doutorado em Moscou, em 1990, e começou a carreira acadêmica como professor e líder do Departamento de Educação Pré-escolar no Instituto de Treinamento Docente de Murmansk entre 1991 e 1997. Obteve um segundo doutorado pela Universidade de Oulu (Finlândia), em 1998. De 1999 a 2011, o autor foi afiliado ao Departamento de Treinamento Docente de Kajaani, na Finlândia, como pesquisador sênior e diretor científico de projetos internacionais.

Atualmente, Nikolai Veresov é professor-associado da Faculdade de Educação da Universidade de Monash, na Austrália, e líder do grupo de pesquisa sobre a primeira infância. As grandes áreas de pesquisa do autor envolvem a educação na primeira infância e a teoria e metodologia histórico-cultural. Entre seus campos de interesse, estão: o desenvolvimento da criança, a teoria e metodologia da pesquisa histórico-cultural na primeira infância, o jogo, a aprendizagem, o desenvolvimento e as funçóes executivas na primeira infância.

O professor Veresov permaneceu 15 dias como pesquisador visitante na cidade de Natal, Brasil, dando mostras de uma disposição infatigável para o diálogo e a troca, que trouxe benefícios para toda a comunidade de estudantes e pesquisadores da Universidade Federal do Rio Grande do Norte (UFRN). A entrevista aconteceu em 13 de julho de 2016, no Instituto Metrópole Digital, e foi conduzida em meio a um movimentado cronograma de atividades, que envolvia conferências, reunióes oficiais com membros da universidade e com professores, para construir laços de cooperação internacional, bem como encontros com estudantes, nos quais eles tinham liberdade para fazer as questôes que quisessem.

O propósito desta entrevista ${ }^{1}$ foi fazer nosso visitante reagir a um conjunto de perguntas formais que refletiam nossos interesses de pesquisa e poderiam aprimorar nosso conhecimento sobre psicologia, tanto de um ponto de vista científico quanto pessoal. As perguntas foram elaboradas por membros de dois grupos de pesquisa em psicologia baseados na UFRN: o Grupo de Estudos e Pesquisas sobre o Trabalho (GEPET) e o Laboratório de Pesquisa e Extensão em Neuropsicologia (LAPEN).

\section{Entrevista}

Entrevistador: Para começar, quero fazer uma pergunta sobre Nikolai Veresov, pesquisador, mas também Nikolai Veresov, o homem. É uma questão inspirada por seu livro Undiscovered Vygotsky (VERESOV, 1999). Você diz nesse livro que Vigotski é um filho da Era de Prata ${ }^{2}$ da cultura russa. E Nikolai Veresov? 
Onde você nasceu e quais foram suas primeiras referências culturais antes de se tornar o especialista em Vigotski mundialmente conhecido que você é hoje? Quais foram suas primeiras leituras, primeiros contatos com a alta cultura que formaram você como pessoa e como pesquisador?

Veresov: A ideia de que Vigotski foi um filho da Era de Prata não foi apenas discutida em meu livro. O livro Understanding Vygotsky: a quest for synthesis, de René van der Veer e Jaan Valsiner, que foi publicado em 1991, foi o primeiro e o melhor naquela época a descrever o contexto histórico e cultural da teoria e da vida de Vigotski (VAN DER VEER; VALSINER, 1991). Os leitores têm acesso a quem foi Vigotski enquanto ser humano, as raízes, qual foi sua biografia, o ambiente sociocultural, e foi um livro muito bom. Então, eu não fui o primeiro a chamar Vigotski de "filho da Era de Prata da cultura russa". No entanto, no meu livro, eu tentei olhar mais de perto e analisar o momento em que Vigotski era jovem, quando ele tinha acabado de começar sua carreira. De certa forma, Vigotski antes de ser Vigotski. Naquela época, o público ocidental tinha pouco conhecimento de Vigotski antes de ser Vigotski. Mas sua teoria não apareceu de uma vez, do nada. Eu pensei que o desafio fundamental para compreender sua teoria era a falta de uma pré-história da teoria histórico-cultural. Em outras palavras, eu queria encontrar respostas para a pergunta "Por que teoria histórico-cultural?". O que Vigotski fez antes de ir para a teoria histórico-cultural? Ele tentou criar várias teorias, mas por que ele não estava feliz com elas, por que ele teve que mudar sua forma de pensar, por que ele não estava satisfeito com as teorias que já existiam em psicologia, quais foram as forças que o moveram além, em direção à teoria histórico-cultural? Meu estudo era sobre a pré-história da teoria histórico-cultural. Foi o primeiro livro desse tipo, discutindo a evolução teórica de Vigotski na sua trajetória para a teoria histórico-cultural. Eu tentei preencher essa lacuna. Mas agora vou me concentrar em Nikolai Veresov. Eu posso contar um pouco sobre o que me fez ser humano e pesquisador, de alguma forma. Primeiro, claro, é a minha família. O ambiente familiar é importante para todos. Minha família era uma família comum de classe média. Minha mãe era assistente social e meu pai, marinheiro, ele visitava países estrangeiros vendendo madeira da União Soviética. Meu pai, Nikolai - essa é razão pela qual me chamo Nikolai Nikolaievitch —, me influenciou bastante, foi ele quem me recomendou estudar inglês. Não fazia nenhum sentido estudar inglês na escola soviética: por que deveríamos estudar inglês quando qualquer conexão com estrangeiros era proibida pela KGB nos anos 1970? A pergunta era por que eu deveria estudar inglês na escola, uma língua que eu nunca usaria na minha vida, certo? Foi meu pai que me disse uma vez: "Nikolai, sabe, os tempos mudam. Pode acontecer que no futuro o seu conhecimento de inglês faça a sua vida". E eu acreditei no meu pai e comecei a estudar inglês individualmente, através de livros, e veja: ele estava certo! Faz 20 anos que o inglês é minha língua de trabalho. E então minha mãe, Raisa Adamovna: minha primeira experiência no teatro foi com ela, quando eu era uma criança na escola 
primária. Era uma cidade chamada Arkhangelsk. Ela me levou para todos os concertos de música clássica, ballet, teatro, e isso me fez um admirador de cultura, de teatro, de poesia etc. E a escola, claro, na cidade de Murmansk. Era uma típica escola soviética, nada de especial, mas, como vocês sabem, o sistema educacional soviético era um dos melhores do mundo e o que era interessante nele é que ele não era focado somente em ideologia comunista, também havia ciências naturais, cultura e literatura. A matéria de literatura russa era uma das mais importantes. Então costumávamos ler como dever de casa Pushkin, Lermontov, Chekhov, Mayakovsky, Dostoyevsky, Tolstoy, eles eram leituras obrigatórias na escola. Assim, havia uma base para conhecer literatura, toda a riqueza da cultura russa, de Pushkin a Mayakovsky. E tive sorte com a professora, minha professora foi Taisia Mogilyanskaya. Ela era professora de física, mas, ao mesmo tempo, era plena de cultura, museus, literatura, música, teatro. Ela era de Leningrado. Todos os feriados ela levava a classe inteira para Leningrado. Durante uma semana visitávamos museus de manhã e teatros à tarde. Esse era o plano para nos educar, as crianças, mas ela era professora de física. Eu considero minha professora Taisia Mogilyanskaya como minha máe na cultura, ela era o tipo de professora... bem, o tipo de grande professora que muda a sua vida. Infelizmente, ela morreu há alguns anos, mas há geraçôes de estudantes em Murmansk que se lembram dela como uma máe, porque ela foi uma pessoa que causou um grande impacto, não apenas na minha vida, mas na vida de muitas geraçóes de estudantes. Então minha vida foi relacionada com a cultura russa, mas não apenas cultura russa, devido a Shakespeare, Byron, por cultura alemá, britânica, francesa, italiana, entáo, digamos, cultura mundial. Um lugar importante era dado ao rock'n'roll também, porque os Beatles afetaram nossa geração. Conheço algumas pessoas que estudaram inglês para entender o que os Beatles estavam cantando, então... Eu estava aprimorando meu inglês e aí cheguei aos estudos, na instituição local de ensino. Havia uma faculdade de treinamento de professores em Murmansk. Minha especialidade era o ensino de história. Meu interesse em história se converteu não em história política, guerras, revoluçóes, mas história da cultura. Para mim, essa era a área mais interessante da história. Tudo muda, a cultura permanece. A história do teatro, por exemplo, teatro grego antigo até o teatro moderno contemporâneo, Stanislavsky e Chekhov. História da poesia, desde poetas antigos, como Homero, até poesia contemporânea, George Byron, ou poesia russa, francesa, Arthur Rimbaud, por exemplo, ainda é um dos meus preferidos, ou o grande poeta espanhol Juan Jimenez. Esse era o território da minha vida. Eu estava vivendo no sistema soviético, mas esse era o território no qual eu me sentia confortável. Meu interesse especial durante meus anos de estudante era a história da filosofia. E novamente encontrei um professor, que era o chefe do departamento de filosofia na faculdade local de Murmansk, seu nome era Jalal Rzaev. Ele foi meu primeiro professor em filosofia, ele me disse que a melhor maneira de desenvolver meu pensamento era lendo os originais, não os manuais sobre a história da filosofia, mas os filósofos mesmo, Platão, Aristóteles. E 
então ele disse: você talvez não entenda nada desses grandes livros, mas está tudo bem, tente ler e tente pensar, tente debater, dizendo "discordo, concordo", tente pensar em diálogo. Foi uma obuchenie muito boa [obuchenie é uma palavra russa para "aprendizado" como uma atividade comum entre um estudante e um professor], não criticar o que havia de errado com a prévia filosofia, mas tentar compreender a lógica de pensamento de grandes filósofos. Era divertido para mim, era muito interessante. Eu não percebi que era uma escola para desenvolver meu próprio pensamento. Você não reflete sobre isso, você apenas faz coisas e então de repente você se dá conta de que entende algumas pessoas e ideias. Esse era o meu território, filosofia, história da filosofia, incluindo Marx, claro. Na união soviética havia apenas uma filosofia oficial, a filosofia marxista, mas, para mim e outros interessados em filosofia, havia muitos grandes filósofos, e Marx era um deles. Teatro e poesia: eu sei muito de cor, de Pushkin a Brodsky, como muitos outros russos também sabem. Eu me sentia bem confortável aí, eu me sentia pertencendo à tradição da cultura russa, literatura russa, história russa, o grande país da Rússia, não em termos de geografia e política, mas a grande história em música, ballet, literatura, poesia, teatro, cinema, em tudo. Sou da Rússia de Pushkin e Dostoyevsky, não da Rússia de Stalin ou Lenin.

Essa foi minha vida pré, digamos, e então comecei minha carreira acadêmica. Tenho três carreiras acadêmicas: a russa, a finlandesa e a australiana. $\mathrm{Na}$ minha primeira vida acadêmica fiz meus estudos de doutorado em Moscou, no período 1987-1991. Meu doutorado foi no campo da primeira infância e foi baseado na teoria da atividade, porque meus professores e supervisor estavam fazendo teoria da atividade e eu estava feliz de fazer isso. Eu amava a teoria da atividade, ainda amo, mas naquele tempo era a única teoria com a qual eu estava trabalhando. Eu estava feliz com isso, mas o que aconteceu? Eu percebi que tinha duas vidas, primeiro minha vida na história da literatura, música, ballet, música clássica, drama (da Rússia e do mundo), e, ao mesmo tempo, enquanto jovem pesquisador e estudante de doutorado, eu estava fazendo uma pesquisa que tinha a teoria da atividade como referencial. Não havia conexóes entre essas duas vidas. E então minha primeira vida acadêmica (russa) acabou, me mudei para a Finlândia e me senti preparado para começar a ler Vigotski, porque na minha primeira vida acadêmica, "vida teoria da atividade", todos nós sabíamos algo sobre Vigotski, todos sabíamos que estávamos fazendo pesquisa vigotskiana, porque a teoria da atividade é uma espécie de continuação de Vigotski. E nos foi dito "Olha, pessoal, claro que vocês podem começar a ler Vigotski, mas cuidado, é extremamente difícil, e você tem de estar preparado, mentalmente e filosoficamente preparado para entrar nessa teoria”. Agora, olhando para trás, posso confirmar - meus professores estavam absolutamente corretos quando disseram que você deve estar preparado para entender toda a profundidade da teoria histórico-cultural. Leontiev e Davydov foram suficientes para eu fazer o meu doutorado. Vigotski, para nós, era como um Deus, guru, e se você é corajoso o suficiente você pode começar a tocar nisso, mas ainda 
é uma grande montanha, como o Mont Blanc. Quando me mudei para a Finlândia me senti preparado para começar a ler realmente Vigotski. Meu privilégio é que posso ler em russo, comecei a ler Vigotski e, ao mesmo tempo, a escrever um livro, Undiscovered Vygotsky. E esse foi um momento da minha vida em que senti que "Sim, agora não tenho mais duas vidas", porque a teoria de Vigotski é sobre cultura, sobre dramas da vida, e mesmo sobre como a cultura molda mentes humanas. Você não precisa mais de duas vidas, Nikolai, você não precisa viver sua vida no contexto cultural e fazer sua pesquisa em teoria da atividade. Essa é a teoria que combina, então eu comecei a fazer pesquisa em Vigotski porque ressoava minha história, meus antecedentes históricos e culturais. A partir desse momento estou feliz porque eu vejo, eu sinto, como a teoria de Vigotski combina cultura e indivíduos e meu mantra é "Mentes humanas são historicamente enraizadas, socialmente construídas e culturalmente moldadas". Estou absolutamente seguro de que minha mente, a mente de Nikolai, é historicamente enraizada, socialmente construída e culturalmente moldada. E ainda está se moldando, não está moldada de uma vez por todas. Então eu publiquei o livro. Aconteceu, eu não estava pronto para ser um... o que você disse? Um "especialista mundialmente conhecido", esse não era meu objetivo. Eu queria entender o que Vigotski queria sugerir para as pessoas, qual era a chave, qual era a mensagem mais importante que ele queria enviar para o mundo inteiro, enquanto psicólogo, para entender como as crianças crescem, como as crianças se desenvolvem, como nós crescemos, como nós nos desenvolvemos, qual o lugar da cultura no nosso desenvolvimento, porque a consciência é algo que só existe na cultura, todas essas coisas interessantes.

Ainda acho que, se você não tem uma base filosófica forte, nunca entenderá Vigotski, mesmo que o russo seja sua primeira língua. Porque Vigotski teve uma base filosófica e cultural muito forte, e, se você não tem esse tipo de base, se você não sabe nada sobre a "Era da Prata" da cultura russa, não há como entender Vigotski. Sua compreensão será muito simplificada, superficial, muito fragmentada. Eu acredito firmemente que o pré-requisito para entender Vigotski é ter um nível de pensamento desenvolvido, o conhecimento da dialética e a compreensão do contexto da Idade da Prata da cultura russa, a linguagem da cultura, a linguagem do teatro, a poesia, a música e, assim por diante. No ano passado, fui convidado para ir a Moscou realizar três dias de palestras intensivas sobre a teoria de Vigotski. O que eu fiz? Comecei a palestra com uma poesia. Eles eram estudantes russos, ficaram chocados porque nunca viram um professor que inicia a palestra dizendo: quem é seu poeta favorito? Você está tentando entender Vigotski, mas você não tem um poeta favorito? O que vou fazer aqui? Então eu disse: se você não se sentir confortável nesse território da cultura, você não terá outra maneira senão entender Vigotski de uma forma muito superficial. Isso é sobre uma opinião de Nikolai, como pessoa.

Entrevistador: Manolis Dafermos me disse uma vez que "Cada país tem seu próprio Vigotski” — veja Dafermos (2015) para uma compreensão mais detalhada -, então, como você vê essas diferentes leituras de Vigotski em diferentes países? 
Veresov: Essa é uma questão interessante e fundamental. É um debate em curso na comunidade vigotskiana, sobre diferentes interpretaçôes de Vigotski, e há duas posiçôes aqui. A primeira posição é que todos têm o direito de interpretar Vigotski como gostarem. Poderia ser a interpretação de Michael Cole de Vigotski, a interpretação de James Wertsch de Vigotski, a interpretação de Jerome Bruner de Vigotski, a interpretação de Armstrong de Vigotski. Qual base filosófica está por trás dessa posição? Impossível ter razão, todos estão certos, existem múltiplas verdades. Respeito muito o pós-modernismo, mas não compartilho essa posição. Tenho uma tradição filosófica diferente atrás de mim: a teoria é algo que não pode ser interpretado da maneira que você deseja. Você pode imaginar interpretação da teoria da relatividade? Os russos interpretarem de um jeito, os americanos de uma forma, os finlandeses de outra forma... Impossível! Por que é possível com a teoria de Vigotski? O que é interessante aqui é que as pessoas que compartilham essa posição dizem: "Não, Vigotski não criou uma teoria, foram apenas insights, ideias teóricas interessantes. Eles não são dados de maneira sistemática, você sabe?". Tenho uma forte convicçáo de que Vigotski criou uma teoria como um sistema de conceitos inter-relacionados, focados no processo de desenvolvimento e, portanto, por isso, náo compartilho a posiçáo que diz que todos podem interpretar a teoria ou o conceito de forma diferente. Porque, se você respeita a teoria, você náo pode interpretar a teoria do jeito que for mais confortável para você. O problema é que a teoria é muito complexa e ainda não descoberta, ninguém fez o trabalho de apresentar a teoria de Vigotski de forma sistemática, como um todo. Porque o próprio Vigotski não fez isso e ninguém depois dele fez isso. Portanto, com todo o respeito às interpretaçôes, prefiro concentrar-me na análise sistemática de toda a teoria de Vigotski e apresentá-la de forma sistemática para jovens gerações de pesquisadores.

Bem, e chegando às metáforas, isso é o que acontece com a teoria de Vigotski: imagine que um cara está dizendo a uma garota: "Oh, minha querida, eu amo seus olhos! Eles são tão lindos!". E a menina responde: "Você ama meus olhos, mas para obter meus olhos você tem de me tomar por inteira, você não pode tomar apenas meus olhos". O mesmo acontece com a teoria de Vigotski. Alguém vem com a teoria de Vigotski e diz: "Eu amo a zona do desenvolvimento proximal" e tira a zona de desenvolvimento próximo da teoria como um todo, da mesma forma que um cavalheiro retira apenas os olhos da garota. Então, o que acontece? A zona de desenvolvimento próximo, que está sendo tirada de toda a teoria, não funciona. Eu publiquei um capítulo chamado: "Forgotten methodology" [Metodologia esquecida], no livro Methodological Thinking in Psychology: 60 years gone astray? [Pensamento metodológico em psicologia: 60 anos se perderam?] (VERESOV, 2010). Lá, faço uma análise do que aconteceu. Meus colegas, ocidentais vigotskianos, às vezes, apenas estâo cortando os fragmentos da teoria e construindo suas próprias teorias sobre isso, e eles dizem: "Estamos desenvolvendo Vigotski”. É como tirar os olhos da menina e dizer: "Estamos desenvolvendo a menina!". Além da fragmentação, há outro perigo: a simplificação, que também 
náo é boa. Bem, o que devemos fazer é apenas um trabalho coletivo duro, para aprofundar nossa compreensão de toda a teoria de forma sistemática. Essa é a tarefa, não só para mim, mas também para toda a comunidade.

Entrevistador: O que deve ser considerado o núcleo duro da psicologia histórico-cultural? Quais conceitos devem ser vistos como parte desse núcleo que não podemos separar da psicologia histórico-cultural porque é a própria essência da teoria?

Veresov: Essa pergunta precisa de esclarecimentos. O conceito de "núcleo duro" foi desenvolvido pelo matemático e filósofo da ciência: Imre Lakatos (LAKATOS, 1989). Por um lado, é uma questâo fácil, por outro lado, é uma questão difícil. Fácil porque temos uma resposta de Vigotski. Se você olhar nos textos de Vigotski, encontrará a resposta. O núcleo duro é o processo de desenvolvimento de funçóes mentais superiores, que é o processo da gênese sociocultural da mente humana. Em outras palavras, o complexo processo dialético de como o social se torna um indivíduo - este é o núcleo. Essa é a resposta simples, mas a resposta complexa, a resposta difícil, envolve responder perguntas como "O que você quer dizer com gênese sociocultural? O que você quer dizer com social torna-se um indivíduo? O que você quer dizer com o processo de desenvolvimento de funçóes psicológicas superiores?". Então, gera uma série de perguntas que você responde gradualmente... E, como resultado, você tem uma visão de toda a teoria, porque toda a teoria é a resposta para essa questão, é por isso que é o núcleo duro. É assim o caminho para reconstruir toda a teoria, mas existe outra maneira interessante, porque a teoria de Vigotski é um sistema de conceitos teóricos. Por exemplo, posso tomar qualquer conceito: posso começar do conceito de zona de desenvolvimento próximo. O que é a zona do desenvolvimento proximal? Para entender a zona do desenvolvimento proximal, tenho que fazer a minha primeira pergunta: o que é desenvolvimento? A resposta a essa pergunta será: o desenvolvimento é um processo de gênese cultural social de funções mentais superiores. Ok, então, qual é o processo? O que é a gênese sociocultural? O que é a função mental superior? E, novamente, uma série de perguntas leva você a toda a teoria. É o que eu chamo de entendimento teórico. A compreensão teórica de cada conceito não é completa se você, como pesquisador, não conseguir reproduzir, reconstituir a relaçáo desses conceitos com toda a teoria. É o que chamamos de pensamento teórico cultural. Isso é muito difícil para algumas pessoas entenderem. Existe uma tradição norte-americana que apenas toma o conceito e faz uma definição simples e, em seguida, joga com a definição, mas há uma diferença entre uma definição e um conceito. Os conceitos têm conteúdo teórico, o que não é o mesmo que a definição do significado. Podemos jogar com definiçóes, todos definem de maneiras diferentes, mas isso é sobre definições, não é sobre o conceito. Os conceitos têm um conteúdo muito forte. Então, para mim, o núcleo duro é a gênese sociocultural da mente humana, que é o processo de desenvolvimento de funçóes mentais superiores, que é o processo de como o social se torna o indivíduo. Além disso, você deve se lembrar do que eu disse, no princípio, cada conceito pode ocupar 
temporariamente o papel de núcleo duro que ajuda você a reconstruir toda a teoria, porque, se você tomar isso... Toda a história se desenrolará. Tire o drama, toda a teoria desaparece, retire a situação social de desenvolvimento, toda a teoria desaparece, todos os conceitos formam um sistema de conceitos relacionados ao processo de desenvolvimento das funçóes mentais superiores.

Entrevistador: Podemos falar sobre teoria, conceitos e não poder fazer algo com eles do ponto de vista do método. Vigotski foi criticado por não ser claro no método. Então, qual é a essência do método genético experimental? Qual é a inovação que traz em comparação com métodos psicológicos clássicos mais antigos?

Veresov: Essa é uma das questões fundamentais, uma das questões e problemas mais importantes hoje em dia com Vigotski. Vigotski desenvolveu uma teoria muito avançada, um sistema de conceitos. Ao mesmo tempo, ele desenvolveu o novo método de análise do processo de desenvolvimento, porque os métodos tradicionais foram focados em aspectos fenomenológicos do desenvolvimento. Não foram capazes de desenvolver todo o processo de desenvolvimento em sua complexidade. Então, eles estavam observando como o fenômeno mudou, o exemplo clássico é Piaget. De um nível a outro nível, diferentes fenômenos que você pode testar, esclarecer e reproduzir, e assim por diante. Portanto, sua tarefa era desenvolver um método em paralelo com o desenvolvimento da teoria e há muitos lugares onde Vigotski escreve que a teoria e o método váo juntos. $\mathrm{O}$ desenvolvimento da teoria náo é bem-sucedido sem o desenvolvimento do método. O desenvolvimento do método é, ao mesmo tempo, o desenvolvimento da teoria, então, eles têm que ir juntos, alfa e ômega. Diante disso, há três, quatro ou cinco referências que, claramente, expressam essa posição, mas o problema era que os trabalhos de Vigotski eram principalmente teóricos, mais focados em conceitos, e pouco ele publicou sobre seu método. Há apenas dois ou três artigos, um capítulo em "A história do desenvolvimento de funçôes mentais superiores" (VYGOTSKY, 1997a) e dois trabalhos separados sobre o método: "O método instrumental em psicologia" é um desses (VYGOTSKY, 1997b) e o outro é "Métodos de estudo de funçóes mentais superiores" (VYGOTSKY, 1999). Bem, o que eu encontrei foi a seguinte imagem: uma teoria muito bem desenvolvida e uma descrição muito geral do método, sem exemplos concretos de como o método funciona. Se você está familiarizado com os textos originais de Vigotski, você verá quão raramente ele usa os dados experimentais, e, quando ele usa, é como uma ilustração de sua pesquisa. Na literatura, em nossa compreensão de Vigotski, era uma lacuna! E há um problema para geraçóes de pesquisadores que estão fazendo pesquisas concretas neste campo, projetos experimentais concretos, como projetos de doutorado ou algo assim, porque não têm instruçóes concretas, requisitos e princípios de como organizar o estudo experimental. $\mathrm{O}$ que eles fizeram? Eles apenas reproduziram o que seus professores fizeram, mas com um novo conteúdo, ou simplesmente fizeram como entendiam, mas eles não estão certos de que o que eles estão fazendo é realmente uma experiência vigotskiana. Não houve clareza sobre como a teoria corresponde ao método de pesquisa. Às vezes, eu vejo artigos como: na primeira parte, pontos de partida 
teóricos completamente vigotskianos. Então, olho para a parte experimental e vejo que todo o experimento é feito de acordo com os procedimentos tradicionais, clássicos e psicológicos aceitáveis para a psicologia geral. Mas náo deve ser assim, porque o método deve estar relacionado com a teoria. E eu levei isso como minha tarefa, com objetivo de preencher essa lacuna. Para tanto, eu colecionei todas as descriçóes experimentais de todos os escritos de Vigotski em inglês e russo, além de encontrar livros de publicaçóes de seus estreitos associados, como, por exemplo, Sakharov e o jovem Leontiev (que fez sua primeira pesquisa em memória sob a supervisão de Vigotski - um estudo histórico-cultural, e mais tarde se mudou para a teoria da atividade). Então eu colecionei todas as descriçōes de experiências de Sakharov, de Vigotski, de Davydov, de Leontiev e foi um arquivo de 350 páginas de descriçóes e entáo eu disse: "O que eu vou fazer com isso?". Eu tentei analisar todos esses protocolos, todos esses procedimentos, tentando encontrar quais são os aspectos semelhantes, quais são os princípios que podem ser aplicados, e foi um trabalho difícil. Finalmente, formulei cinco princípios ${ }^{3}$ de metodologia de pesquisa genética, esse foi o meu modesto contributo (VERESOV, 2014). Eu acho que fiz um bom trabalho para a comunidade e estou feliz que agora mais e mais pesquisas na Austrália e em todos os lugares estáo seguindo esses cinco princípios, que são princípios específicos de como organizar pesquisas experimentais concretas sobre o método de pesquisa genética, pois são focados na questão de pesquisa e seus links para os conceitos. A metodologia de pesquisa histórico-cultural é um sistema de ferramentas teóricas de análise e princípios experimentais de design do experimento, todos juntos. Eles criam o que chamamos de metodologia de pesquisa genética histórico-cultural ou simplesmente Metodologia de Pesquisa Genética (GRM), porque a metodologia não é apenas uma combinação de procedimentos metodológicos concretos, esta é a compreensão norte-americana de metodologia. Eles perguntam "Qual é a sua metodologia?”. Em outras palavras: mostre-me que procedimentos metodológicos concretos você usou, como observação, entrevista, questionário etc. Mas a compreensão germânica, europeia, de metodologia é que tipo de ferramentas teóricas e experimentais você utiliza em conjunto para criar sua pesquisa, para criar seu design experimental. Então, o que eu fiz? Eu apenas converti descriçóes gerais apresentadas por Vigotski em princípios concretos de organização e design, e coleta de dados e análise de dados, que eu acho que são muito úteis. A primeira publicação desses princípios ocorreu há dois anos, em 2014, e eu vejo o interesse da comunidade em usar esses princípios como guia. Mas retornando ao geral, reduzindo, Vigotski nomeou seu método experimental de método genético, e a diferença central é que esse método genético não é um método focado em como descrever o processo, mas como explicar o processo de gênese sociocultural da mente humana. Eu posso olhar uma maçã e eu posso descrever uma maçã, a forma da maçã, a cor da maçã, o sabor, a estrutura, eu posso fazer muitas coisas sobre isso, mas mesmo a descrição completa da maçã não me ajudará a compreender, explicar, por que ela tem as características que tem. A única maneira é olhar a história completa do crescimento da árvore, folhas, e então dos botôes, das flores e, depois, da maçã e assim isso me 
ajudará a entender por que ela se aparenta dessa forma. Em vez de descrever, eu estou explicando todo o caminho de aparecimento da maçã. Essa é a diferença dos métodos tradicionais focados na descrição do fenômeno para a abordagem vigotskiana preocupada em explicar o fenômeno, não somente os frutos do desenvolvimento, mas o processo completo da árvore inteira que produz frutos. Entáo, genético. Por que genético? Porque seu enfoque é a gênese. Por que experimental? Porque você pode reproduzir esse método genético em laboratório, em condiçóes especialmente criadas, artificialmente, você pode tornar o desenvolvimento visível, por exemplo, você pode criar condiçóes para que as crianças executem uma tarefa de lembrar algo, e, se elas náo conseguem, elas começam a utilizar objetos em seu entorno como instrumentos para lembrar. Por exemplo, você entrega a elas isso [uma folha de papel] e pergunta: "Como você poderia usar?". Você pode cortá-la em pedaços e usá-la como um, dois, três, quatro... Para lembrar... Assim, você pode reproduzir esse processo porque na vida real as pessoas fazem uso de vários instrumentos para desenvolver sua memória cultural. $\mathrm{O}$ processo da transição do não mediado para o mediado, o processo de atividade de mediação pode ser organizado especialmente, nós podemos gerar desenvolvimento em condiçôes artificiais especiais. Os psicólogos "clássicos" poderiam afirmar: "Nós queremos conhecer o processo objetivo e natural do desenvolvimento. Você está falando de condiçóes artificiais? Onde está a natureza?". E a resposta é: "Onde estáo as mentes humanas? São elas naturais ou artificiais? O que são as linguagens? São elas naturais ou artificiais?”. Elas são criadas por geraçóes de pessoas. Todas as mentes humanas são artificiais, essa é a natureza, a segunda natureza da mente humana. Nós pensamos usando a linguagem, mas a linguagem é artificial, logo, nosso pensamento não é um processo natural, e sim artificial porque é mediado pela linguagem - é culturalmente formatado e socialmente construído. Construído através dos sistemas de interação e interações sociais em nossas vidas. Condiçôes artificialmente criadas são apenas condições culturais especialmente criadas. Se você segue a linha de Vigotski, nada é estranho à palavra "artificial". As funçôes psicológicas superiores não são funções psicológicas naturais, elas são funçōes psicológicas sociais, funçôes psicológicas artificialmente criadas, tornando-se parte do nosso mundo interno, mas elas são sociais em sua origem. Sua fonte é social. E tudo que é social é artificial. Essa é a diferenciação entre os métodos tradicionais e o método vigotskiano. Os métodos tradicionais olham para a mente como algo natural, biológico, atrelado ao cérebro. Já a abordagem de Vigotski toma a mente enquanto um sistema artificial, socialmente construído, historicamente enraizado e culturalmente formatado. E o cérebro participa criando novos neurossistemas que tornam isso possível de existir. Mas o cérebro náo gera consciência. Interaçôes sociais, contextos sociais geram consciência. Essa é a diferença.

Entrevistador: Nós ainda não conhecemos o trabalho de Vigotski muito bem, como você mesmo afirma, ele permanece desconhecido. Que novidades a investigação dos arquivos pode descobrir e em que isso pode acrescentar à discussão do legado desse autor? 
Veresov: Essa é uma pergunta bastante interessante. Quando Vigotski morreu, ele deixou vários manuscritos não publicados, livros, artigos também não publicados, diários, diários de pesquisa, os protocolos dos seus trabalhos com crianças, necessidades especiais, defectologia, os protocolos das conferências de pesquisa com Luria e Leontiev, bem como com outros colaboradores que trabalhavam em sua equipe. É um acervo extenso. E muito disso foi mantido em família. A família de Vigotski era sua filha, Gita Vygodskaya, e sua neta, Elena Kravtsova. Elena Kravtsova é agora docente de psicologia e diretora do Instituto Vigotski. Há um Instituto Vigotski em Moscou que é parte da Universidade de Humanidades de Moscou. E tal acervo permaneceu como propriedade privada da família porque Vigotski foi banido nos anos de 1930-1950 e eles náo podiam enviar esses materiais para livrarias ou para o arquivo governamental. Dez anos atrás, em uma situação fenomenal de crescente interesse pela teoria vigotskiana, a família começou a pensar no que fazer com esse acervo. Eles queriam que alguém viesse, um especialista em acervos, para sistematizar os materiais e digitalizar o acervo, traduzir essas notas curtas em uma forma mais legível. A ideia era abrir esse arquivo na forma de publicação de novos trabalhos reunidos de Vigotski. Havia seis volumes em russo, trabalhos reunidos publicados em 1982-1984, e, por causa do extenso acervo, a ideia era publicar novas ediçôes, em 16 volumes, para reproduzir aqueles seis volumes, mas sem qualquer acréscimo, qualquer censura, os textos originais com todos os manuscritos não publicados, diários, planos de artigos, notas etc. $\mathrm{O}$ time editorial começou a trabalhar, esse era um projeto bem promissor. Eu fiquei feliz de Elena Kravtsova ter me convidado para ser um dos editores de um dos volumes, para compor o quadro editorial desse trabalho. O que aconteceu durante esses dez anos foi um imenso trabalho de transcrição das notas em um formato mais legível. E o processo continua. $\mathrm{O}$ primeiro volume foi publicado no começo desse ano (VYGOTSKY, 2015 ${ }^{4}$ ). Cento e vinte anos do aniversário de Vigotski. Eu estava envolvido no volume quatro e estava trabalhando junto com uma jovem pesquisadora, Ekaterina Zavershneva. Ela é psicóloga, mas, quando começou a trabalhar, ela não era da linha vigotskiana, ela foi apenas convidada para fazer o trabalho, para sistematizar o acervo. Contudo, enquanto ela trabalhava com essas notas, ela se tornou vigotskiana e agora, em dez anos, ela é uma das melhores experts em acervos vigotskianos. Ela publicou vários artigos em russo e inglês apresentando trechos dos arquivos de Vigotski (ZAVERSHNEVA, 2010a; 2010b; 2010c), que eram absolutamente desconhecidos do público, com comentários científicos bem interessantes, com um conhecimento profundo. Ela também publicou alguns capítulos em inglês sobre o acervo de Vigotski, apresentando alguns excertos com comentários. $\mathrm{O}$ acervo contém alguns artigos absolutamente desconhecidos de Vigotski antes de ele ter começado sua carreira em Moscou. Nós todos conhecemos a história de Vigotski. Ele foi para São Petersburgo para se apresentar na Conferência de 1924. Ele apresentou seu discurso na conferência e Luria estava lá assistindo. Luria ficou tão impressionado com aquela palestra, que ele abordou Vigotski e o convidou para vir ao Instituto de Psicologia de Moscou. Mas, é claro, nós 
sabemos que essa não é a história correta, porque Vigotski tinha uma "pré-história". Ele estava em Moscou como um estudante e participava na vida cultural. Ele era, em Moscou, filho da Era de Prata da cultura russa. Sergei Eisenstein, o diretor de filmes, era seu amigo. Osip Mandelstam, o famoso poeta russo, era seu amigo. Seu professor, Yuly Aikhenvald, era secretário do periódico Questóes de Filosofia e Psicologia. Ele estava ativamente imerso em toda a vida cultural. E aí a Revolução, então ele foi para Gomel e foi professor, e depois voltou para Moscou. Assim, retornando para a palestra legendária em São Petersburgo, em 1924, o que é interessante é como Luria relembra esse evento: "Quando fui até ele, após sua apresentação, Vigotski parecia estar lendo. Eu olhei o papel, mas estava em branco". No entanto, no acervo, a palestra existe de modo escrito. Eu não quero contar-lhes a história completa, mas, quando nós soubermos tudo sobre isso, nós teremos absolutamente outro Vigotski. E esse é o motivo pelo qual, a propósito, eu não comecei a escrever meu livro sobre a teoria histórico-cultural, porque, quando nós soubermos a história por inteiro, todos os materiais publicados, talvez nós percebamos que a teoria de Vigotski é muito mais complexa. Talvez haja muitos mais conceitos que nós não conhecemos ainda. Por outro lado, há algumas tentativas de criar certas, como posso dizer, tolices em torno da produção vigotskiana. Eu prefiro o trabalho analítico, sistemático, a partir de conhecimento aprofundado, a partir dos materiais do acervo com relação ao quadro que temos agora. Como os novos achados do acervo nos ajudaráo a melhor compreender a teoria vigotskiana?

Entrevistador: Agora nós faremos algumas questôes sobre perezhivanie. Nossas relações sociais podem existir sem perezhivanie? O que não é perezhivanie? Há algum critério para se afirmar "Isso é perezhivanie, isto não é"?

Veresov: Começarei com minha preocupação com perezhivanie. Temo que, para alguns pesquisadores, perezhivanie seja tomado como um novo brinquedo, uma vez que a velha história chamada zona de desenvolvimento próximo está ficando entediante. Entretanto, conceitos não são joguetes, conceitos têm um conteúdo bem denso. Existe a história de incompreensão da zona de desenvolvimento próximo de Vigotski nos últimos 25 anos, e somente nos últimos cinco anos algumas pessoas começaram a pensar sobre o real teor da zona de desenvolvimento próximo, restabelecendo a verdadeira complexidade e o real conteúdo teórico dessa noção. Eu quero que perezhivanie seja aceito na comunidade científica enquanto conceito, tendo certo conteúdo teórico exato. Você não pode mudar a definição do conceito voluntariamente. E esse é o problema com perezhivanie, porque a parte mais difícil é entender qual é o conteúdo do conceito teórico de perezhivanie. Não se trata de significado, e sim de conteúdo teórico. Esse desafio é importante. Ocorrem agora vários debates sobre perezhivanie, quase todo mundo está falando sobre isso. O periódico Mind, Culture, and Activity publicou uma edição especial sobre perezhivanie esse ano (v. 23, n. 4, 2016). No Congresso ISCAR 2014, em Sidney, nós tivemos três sessōes especiais sobre perezhiva- 
nie e cinco apresentações, há muitas publicaçóes e indicaçóes, Ferholt, Harry Daniels, Fernando Gonzalez-Rey, Marilyn Fleer e alguns outros trabalhando atualmente com esse conceito. Há vários debates. No entanto, minha humilde questão é: "Ainda estamos interessados no que Vigotski conceitua como perezhivanie?". E o que eu tenho feito nos últimos três anos ativamente é esse trabalho de reconstruir, de restaurar, de tornar claros o contexto e o conteúdo original do conceito de perezhivanie, como apresentado nos próprios escritos de Vigotski. E todo meu trabalho agora é reconstruir o teor do conceito e identificar os elos de como ele está relacionado com outros conceitos. Qual é o lugar dessa noção de perezhivanie dentro do sistema completo de outros conceitos? Há uma regra mágica para compreensão: se você quer entender uma noção na teoria vigotskiana, sua primeira tarefa é identificar o lugar desse conceito na teoria e relacionar com outras noçóes, e a segunda tarefa é identificar com quais aspectos do processo de desenvolvimento ele está relacionado. Esse é o caminho da reconstrução teórica. A primeira coisa que é importante distinguir são os dois entendimentos sobre perezhivanie. Perezhivanie como um fenômeno psicológico, que nós podemos observar, estudar, experienciar, investigar de algum modo. E o segundo é perezhivanie como um conceito teórico. A palavra é a mesma, mas os significados são distintos. Não apenas significados são distintos, mas realidades são distintas. Perezhivanie enquanto um fenômeno é uma realidade empiricamente observável. Mas, se nós tomamos perezhivanie como um conceito, não haverá nada de fenomenológico aí. Não há nada empírico porque conceitos são pura abstração teórica. Às vezes, Vigotski em seus escritos usa perezhivanie como um fenômeno, por exemplo, todo o livro de A Psicologia da Arte (VYGOTSKY, $1971)$ é sobre perezhivanie artística, mas somente com um fenômeno, reação estética. Às vezes, ele usa em seus escritos perezhivanie como um conceito, por exemplo: The Problem of age (VYGOTSKY, 1998b), The Crisis at age seven (VYGOTSKY, 1998a). Toda vez que você encontrar a palavra perezhivanie nos textos de Vigotski, a primeira questão [a ser colocada] é: "Trata-se do fenômeno ou se trata do conceito?”. O mais difícil é para os leitores ocidentais, porque perezhivanie foi traduzida, algumas vezes, como "experiência”, outras, como "experimentar". Mas experiência tem outra conotação, por exemplo, experiência passada. O que não tem a ver com perezhivanie. Em russo, diz-se opyt. É perezhivanie e opyt para uma experiência no passado. Nas traduçóes inglesas, opyt e perezhivanie são traduzidas como experiência. E você nunca sabe quando Vigotski refere-se a opyt ou perezhivanie, porque experiência é a tradução, então o quadro torna-se mais complexo. Toda vez que eu vejo experiência em inglês, eu abro o texto em russo e vejo qual palavra Vigotski usou. Foi opyt ou perezhivanie? Se foi perezhivanie, em que sentido? Fenomenológico ou teórico? Esta foi minha primeira contribuição para o campo, separar fenômeno e conceito. O segundo ponto foi explicar 
para a comunidade que nem tudo o que Vigotski escreveu sobre perezhivanie foi uma compreensão histórico-cultural de perezhivanie. Vigotski e Varshava publicaram um pequeno dicionário chamado Psychological Dictionary em 1931 (VARSHAVA; VYGOTSKY, 1931). Naquele tempo, Vigotski já havia desenvolvido sua teoria histórico-cultural. Foi uma pequena nota na letra "P" denominada Perezhivanie e cinco linhas de explanação. Vigotski escreve: "Perezhivanie é todo tipo de opyt, opyt psicológica, experiência que você tenha”, "Todo processo psicológico é perezhivanie". O que significa: percepção visual, memória, pensamento, emoçóes, imaginação, tudo é perezhivanie. Mas esse era um dicionário criado para estudantes, para os fins da psicologia stalinista. Nesse dicionário, Vigotski e Varshava apresentaram toda a terminologia tradicional de diferentes disciplinas psicológicas para os estudantes usarem como complemento para seus estudos em psicologia. Náo era um dicionário de teoria histórico-cultural. Era um dicionário de termos existentes na psicologia tradicional da época. Na teoria histórico-cultural, perezhivanie possui significados diferentes. Náo considere tudo que Vigotski escreveu como teoria histórico-cultural, porque algumas publicaçóes de Vigotski não têm relação com o tema. No capítulo The problem of environment (VYGOTSKY, 1994), Vigotski diz: "Perezhivanie é um conceito". Um conceito teórico que nos permite estudar o papel e a influência do ambiente social no curso do desenvolvimento infantil em relação às leis do desenvolvimento. Esta é a proposta de Vigotski. Ele nos diz: "Esqueça sobre fenomenologia, perezhivanie na minha teoria é um conceito que você pode usar para entender o papel do ambiente no desenvolvimento da criança em relação às leis do desenvolvimento". Isso é um aviso para nós. E essa pergunta precisa de esclarecimento: "O que significa papel do ambiente social? O que significa o conceito? O que significa o ambiente social, o curso do desenvolvimento e assim por diante?". Siga o conselho de Vigotski, a linha de Vigotski. Eu tentei reconstruir todo o conteúdo do conceito de perezhivanie utilizando diferentes escritos de Vigotski e tentando esclarecer isto. Eu segui estritamente as palavras de Vigotski: "Perezhivanie é um conceito que nos permite estudar o papel e a influência do ambiente social no curso do desenvolvimento da

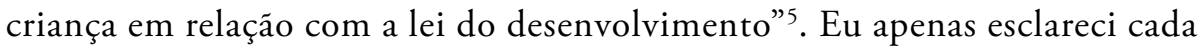
componente dessa orientação, para dizer de forma simples. Mas, claro, é um trabalho difícil. Se vocês querem saber mais sobre isso, minha recomendação é verificar o número especial da Mind, Culture, and Activity (v. 23, n. 4, 2016) sobre perezhivanie, com Fernando Gonzalez-Rey, Beth Ferholt, Harry Daniels e outros. Nele há um artigo de Nikolai Veresov e Marilyn Fleer sobre perezhivanie como conceito (VERESOV; FLEER, 2016) e como esse conceito pode ser usado como uma ferramenta teórica para compreender o papel do ambiente no curso do desenvolvimento de crianças pequenas. Nós apresentamos o conceito e exemplos, como ele funciona. 
Se vocês estão interessados na minha pesquisa sobre perezhivanie, há links de vídeos no meu website pessoal (VERESOV, n.d.). Estou feliz de dizer que meu artigo sobre o problema da perezhivanie como um conceito teórico da teoria histórico-cultural foi aceito pela revista Cultural-Historical Psychology (VERESOV, 2016). E, se vocês puderem aguardar um pouco mais, esperamos publicar no próximo ano o livro Perezhivanie, Emotions and Subjectivity: Advancing Vygotsky's Legacy, coeditado por mim, Marilyn Fleer e Fernando Gonzalez-Rey [a publicação em questão já se encontra disponível: FLEER; GONZÁLEZ-REY; VERESOV, 2017]. Esse livro tem três seções: perezhivanie, emoçóes e subjetividade. Na seçáo sobre perezhivanie, vocês encontrarão meu capítulo, completamente teórico, sobre o conteúdo do conceito de perezhivanie em relação a todos os outros conceitos da teoria histórico-cultural, seguido pelo trabalho da minha colega, Marie Hammer, com o exemplo de como esse conceito nos permite entender alguns aspectos do desenvolvimento infantil na primeira infância e o papel do ambiente social.

Entrevistador: Vigotski usa a metáfora do prisma para falar sobre perezhivanie. Como você interpreta essa metáfora?

Veresov: Olha, eu acho que a melhor forma é ler o número especial sobre perezhivanie na MCA, porque no nosso artigo lá nós discutimos o papel da perezhivanie como uma metáfora de prisma. E também o livro que será publicado (com Gonzalez-Rey e Fleer). Qual o princípio mais fundamental da psicologia como uma ciência experimental que estuda percepção, memória, pensamento etc.? O princípio da reflexão ${ }^{6}$. Ainda é uma resposta, externa e interna. Pode ser reflexão fisiológica, o reflexo de Pavlov é reflexão; pode ser reflexão psicológica, como um estímulo reflete em nós. Então, este é o princípio básico, o princípio da reflexão. Vocês podem dizer que reflexão não é um processo passivo, é um processo ativo, e várias coisas do gênero, apenas para escapar dessa compreensão primitiva de reflexão. Mas a reflexão permanece como um princípio fundamental básico em todo tipo de psicologia experimental. Nós criamos alguns estímulos que, de algum modo, afetam e geram uma reação, pode ser reação em movimento, pensamento, emoção, o que for. Ninguém duvida disso. A única discussão é sobre interpretação, como você interpreta a reflexão. É um processo passivo ou ativo? É um processo complexo ou simples? Quais são os níveis de reflexão, como eles interagem, veja... O que Vigotski fez, Vigotski realmente fez uma revolução. "Perezhivanie é um prisma que refrata tudo que acontece com a criança e que refrata a influência social", não reflete, mas refrata, como a luz que passa por um prisma. Um novo princípio fundamental de refração foi introduzido. Ele usou a metáfora do prisma porque prisma é aquilo que refrata. Essa foi uma metáfora forte, porque desafiou o princípio fundamental básico da reflexão em que toda a psicologia está construída, historicamente, metodologicamente, teoricamente, experimentalmente. O que reflete? Espelho. Introduzindo uma nova metáfora, 
Vigotski está substituindo essa metáfora básica do espelho pela metáfora do prisma. Mas a diferença entre o espelho e o prisma é que o espelho apenas reflete, enquanto o prisma refrata, trazendo mudanças. A luz não passa através do espelho, mas a luz passa através do prisma, reorganiza-se e torna-se diferente, mudando de direção. O processo de atravessar... A propósito, uma das traduções de perezhivanie é atravessamento emotivo [emotional living through], quando a criança passa por alguma situação dramática, e a metáfora do prisma é que a luz passa através do prisma, o que significa que a criança atravessa as dificuldades. Vigotski apresentou essa ideia de prisma, mas ele não desenvolveu seu conceito de perezhivanie como um prisma, foi apenas uma sugestão. Mas introduzir um novo princípio básico para toda a psicologia requer um longo caminho de compreensão e reconstruçáo. Repensar um monte de coisas que decorrem ou podem decorrer do novo princípio. E, de fato, tivemos de repensar de algum modo toda a psicologia. E ninguém pode fazê-lo individualmente. Então, qual teria sido a diferença entre a psicologia construída sob o princípio da refraçáo comparada à psicologia construída sob o princípio da reflexão? Seria definitivamente uma psicologia diferente, mas nós devemos construir essa nova psicologia porque os princípios foram apenas introduzidos. Essa é uma tarefa para as gerações futuras.

\section{Notas}

1. A entrevista foi filmada, transcrita e reduzida a um tamanho administrável passível de corresponder às normas para publicação em uma revista acadêmica. Decidimos manter alguns coloquialismos a fim de transmitir a espontaneidade do discurso oral. Deixamos registrado nosso agradecimento a Nikolai Veresov pela revisão da versão final. Agradecemos também à Coordenaçáo de Aperfeiçoamento de Pessoal de Nível Superior (CAPES) e à Secretaria de Relaçóes Internacionais e Interinstitucionais da UFRN, pelo financiamento que tornou possível a vinda de Nikolai Veresov enquanto professor visitante.

2. A divisão da literatura russa em duas eras é tradicionalmente utilizada por diversos autores, sem que seja possível determinar com absoluta precisão sua dataçáo. De um modo geral, podemos afirmar que a chamada era de ouro está ligada ao começo do século XIX e ao nome do poeta Alexander Pushkin, enquanto a era de prata se situa no período do fim do século XIX e início do século XX. Para Veresov (2005), a era de prata é um período de renascimento das artes e da cultura tragicamente interrompido pelos bolcheviques em 1917.

3. Os cinco princípios mencionados são: 1) botôes de desenvolvimento: a partir da metáfora de botões, flores e frutos, esse princípio significa que é preciso estudar funções psíquicas em seu estágio inicial, e não final de desenvolvimento; 2) interação de formas ideais e reais: o desenvolvimento se dá a partir da interação social que proporciona formas ideais, como a linguagem da mãe para uma criança que apenas balbucia as primeiras palavras; 3 ) categoria 
(colisão, evento dramático): uma determinada relação social dramática deve ser proporcionada, pois as funções mentais superiores aparecem primeiro como categorias interpsíquicas para depois se transformarem em intrapsíquicas; 4) ferramentas desenvolvimentais: no estudo experimental do desenvolvimento a criança deve descobrir, criar e dominar ferramentas mediadoras da sua ação; 5) resultados sustentáveis: o processo de desenvolvimento significa náo somente o surgimento de resultados qualitativamente novos, mas uma nova estrutura de funções que indica uma reorganização sistêmica.

4. Mesmo que se diga 2015, o livro apareceu de fato em 2016.

5. A frase exata é "Experiência (perezhivanie) é um conceito que nos permite estudar o papel e influência do ambiente no desenvolvimento psicológico das crianças na análise das leis do desenvolvimento" (VYGOTSKY, 1994, p. 343, tradução nossa).

6. Ao falar em "princípio da reflexão", Veresov refere-se a uma lógica de reflexo, como ocorre no caso de um espelho, por exemplo, que reflete a realidade que lhe é apresentada. Trata-se de uma lógica de estímulo-resposta, em que um elemento objetivo produz um reflexo subjetivo.

\section{Referências}

DAFERMOS, M. Critical reflection on the reception of Vygotsky's theory in the international academic communities. In: SELAU, B.; CASTRO, R. F. (orgs.). Cultural historical approach: educational research in different contexts. Porto Alegre: EDICPUCRS, 2015. p. 19-38.

FLEER, M.; GONZÁLEZ REY, F.; VERESOV, N. (orgs.). Perezhivanie, Emotions and Subjectivity: Advancing Vygotsky’s Legacy. Singapura: Springer, 2017.

LAKATOS, I. The methodology of scientific research programmes: philosophical papers. Cambridge: Cambridge University Press, 1989. v. 1.

TOASSA, G.; SOUZA, M. P. R. de. As vivências: questôes de tradução, sentido e fontes epistemológicas no legado de Vigotski. Psicologia USP, v. 21, n. 4, p. 757-779, 2010. http://dx.doi.org/10.1590/S0103-65642010000400007

VAN DER VEER, R.; VALSINER, J. Understanding Vygotsky: A quest for synthesis. Oxford: Blackwell, 1991.

VARSHAVA, B.; VYGOTSKY, L. S. Psihologicheskii slovar. Moscou: Gosudarstvennoye Uchebno-pedagogicheskoye Izdatelstvo, 1931.

VERESOV, N. Forgotten methodology: Vygotsky's case. In: TOOMELA, A.; VALSINER, J. (orgs.). Methodological Thinking in Psychology: 60 Years Gone Astray? Charlotte: Information Age Publishing, 2010. p. 267-295.

VERESOV, N. Marxist and non-Marxist aspects of the cultural-historical psychology of L. S. Vygotsky. Outlines, v. 7, n. 1, p. 31-49, 2005.

VERESOV, N. Nikolai's open lectures and conference keynote speeches. Personal site. Disponível em <http://www.nikveresov.net/417149701>. Acesso em: 13 mar. 2019. 
VERESOV, N. Perezhivanie as a Phenomenon and a Concept: Questions on Clarification and Methodological Meditations. Cultural-Historical Psychology, v. 12, n. 3, p. 129148, 2016. https://doi.org/10.17759/chp.2016120308

VERESOV, N. Refocusing the Lens on Development: Towards Genetic Research Methodology. In: FLEER, M.; RIDGWAY, A. (orgs.). International perspectives on early childhood education and development: visual methodologies and digital tools for researching with young children. Cham: Springer, 2014. p. 129-149.

VERESOV, N. Undiscovered Vygotsky: Etudes on the pre-history of cultural-historical psychology. Frankfurt am Main: Peter Lang, 1999.

VERESOV, N.; FLEER, M. Perezhivanie as a Theoretical Concept for Researching Young Children's Development. Mind, Culture, and Activity, v. 23, n. 4, p. 325-335, 2016. http://doi.org/10.1080/10749039.2016.1186198

VYGOTSKY, L. S. The problem of the environment. In: VAN DER VEER, R.; VALSINER, J. (orgs.). The Vygotsky Reader. Cambridge: Blackwell, 1994. p. 338-354.

VYGOTSKY, L. S. The History of the Development of Higher Mental Functions. Nova York: Plenum, 1997a. v. 4. (The Collected Works of L. S. Vygotsky).

VYGOTSKY, L. S. The instrumental method in psychology. Nova York: Plenum, 1997b. p.85-89. v. 3. (The Collected Works of L. S. Vygotsky).

VYGOTSKY, L. S. The Crisis at age seven. Nova York: Plenum, 1998a. p. 187-205. v. 5. (The Collected Works of L. S. Vygotsky).

VYGOTSKY, L. S. The problem of age. Nova York: Plenum, 1998b. p. 289-296. v. 5. (The Collected Works of L. S. Vygotsky).

VYGOTSKY, L. S. Methods of Studying Higher Mental Functions. New York: Plenum, 1999. p. 57-60. v. 6. (The Collected Works of L. S. Vygotsky).

VYGOTSKY, L. S. Polnoye sobranie sochinenii. Moscou: Lev Publishers, 2015. v. 1.

VYGOTSKY, L. S. The psychology of art. Cambridge: MIT Press, 1971.

ZAVERSHNEVA, E. I. The Vygotsky Family Archive: New Findings (1912-1934). Journal of Russian \& East European Psychology, v. 48, n. 1, p. 14-33, 2010a. https:// doi.org/10.2753/RPO1061-0405480101

ZAVERSHNEVA, E. I. The Vygotsky Family Archive: New Findings - Notebooks, Notes, and Scientific Journals of L.S. Vygotsky (1912-1934). Journal of Russian \& East European Psychology, v. 48, n. 1, p. 34-60, 2010b. https://doi.org/10.2753/RPO1061$\underline{0405480102}$

ZAVERSHNEVA, E. I. The Way to Freedom (On the Publication of Documents from the Family Archive of Lev Vygotsky). Journal of Russian and East European Psychology, v. 48, n. 1, p. 61-90, 2010c. https://doi.org/10.2753/RPO1061-0405480103 


\section{SOBRE OS AUTORES}

Flávio Fernandes Fontes é doutor em Psicologia pela Universidade Federal do Rio Grande do Norte (UFRN). Professor adjunto do curso de Psicologia da UFRN, campus de Santa Cruz (FACISA).

Jorge TARcísio da Rocha Falcão é doutor em Psicologia da Aprendizagem e do Desenvolvimento pela Universidade de Paris-V. Professor titular de Psicologia Cognitiva pela Universidade Federal do Rio Grande do Norte (UFRN).

Letícia Raboud Mascarenhas de Andrade é mestre e doutoranda em Psicologia pela Universidade Federal do Rio Grande do Norte (UFRN).

Priscila Cristine Andrade de Sousa é mestre e doutoranda em Psicologia pela Universidade Federal do Rio Grande do Norte (UFRN).

José Arnaud Marques Júnior é psicólogo pela Universidade Federal do Rio Grande do Norte (UFRN).

Recebido em 31 de agosto de 2017.

Aceito em 30 de outubro de 2018. 